PAPers in Physics, VOL. 13, ART. 130005 (2021)

www.papersinphysics.org

Received: 7 June 2021, Accepted: 21 August 2021

Edited by: F. Melo

Licence: Creative Commons Attribution 4.0

DOI: https://doi.org/10.4279/PIP.130005

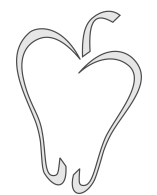

ISSN 1852-4249

\title{
The impact of titanium oxide nanoparticles and low direct electric current on biofilm dispersal of Bacillus cereus and Pseudomonas aeruginosa: A comparative study
}

\begin{abstract}
Mamdouh M. Shawki $^{1 *}$, Marwa M. Eltarahony ${ }^{2}$, Maisa E. Moustafa ${ }^{1}$
Bacteria growing in biofilms cause a wide range of environmental, industrial and public health risks. Because biofilm bacteria are very resistant to antibiotics, there is an urgent need in medicine and industry to develop new approaches to eliminating bacterial biofilms. One strategy for controlling these biofilms is to generate an antibiofilm substance locally at the attachment surface. Direct electric current (DC) and nanoparticles (NPs) of metal oxides have outstanding antimicrobial properties. In this study we evaluated the effect of titanium oxide nanoparticle $\left(\mathrm{TiO}_{2}-\mathrm{NP}\right)$ concentrations from 5 to $160 \mu \mathrm{g} / \mathrm{mL}$ on Bacillus cereus and Pseudomonas aeruginosa biofilms, and compared this with the effect of a $9 \mathrm{~V}, 6$ $\mathrm{mA} \mathrm{DC}$ electric field for 5, 10 and $15 \mathrm{~min}$. $\mathrm{TiO}_{2}-\mathrm{NPs}_{\text {sere }}$ characterized using transmission and scanning electron microscopes, X-ray diffraction and FTIR. They exhibited an average size of $22-34 \mathrm{~nm}$. The $\mathrm{TiO}_{2}-\mathrm{NP}$ concentrations that attained LD50 were $104 \pm 4 \mu \mathrm{g} / \mathrm{mL}$ and $63 \pm 3 \mu \mathrm{g} / \mathrm{mL}$ for $B$. cereus and $P$. aeruginosa, respectively. The eradication percentages obtained by DC at 5,10 , and 15 min exposure were $21 \%, 29 \%$, and $33 \%$ respectively for $B$. cereus and $30 \%, 39 \%$, and $44 \%$ respectively for P. aeruginosa. Biofilm disintegration was verified by exopolysaccharide, protein content and cell surface hydrophobicity assessment, as well as scanning electron microscopy. These data were correlated with the reactive oxygen species produced. The results indicate that both $\mathrm{DC}$ and $\mathrm{TiO}_{2}-\mathrm{NPs}_{\mathrm{s}}$ have a lethal effect on these bacterial biofilms, and that the DC conditions used affect the biofilms in a similar way to $\mathrm{TiO}_{2}-\mathrm{NPs}$ at concentrations of $20-40 \mu \mathrm{g} / \mathrm{mL}$.
\end{abstract}

\section{Introduction}

Bacterial biofilms are clusters of bacteria that are attached to a surface and/or to each other and embedded in a self-produced matrix [1]. The biofilm matrix consists of extracellular polysaccha-

*mamdouh971@hotmail.com

1 Medical Biophysics Department, Medical Research Institute, Alexandria University, 165 Alhorya Avenue, Alexandria city, Egypt.

2 Environmental Biotechnology Department, Genetic Engineering and Biotechnology Research Institute, City of Scientific Research and Technological Applications (SRTACity), Alexandria city, Egypt. rides (EPS), proteins, glycopeptides, nucleic acids, and lipids [2]. Compared with planktonic forms, organisms in biofilms resist undesirable physical, chemical and biological factors in the environment, host immune system, and antimicrobial therapy [3]. Therefore, the susceptibility of bacteria in biofilms to antimicrobial agents is 500-5000 times lower than that of bacteria in suspension (planktonic) cells of the same microorganism [4]. This resistance is due to restricted penetration of the biofilm matrix, the presence of antimicrobial enzymes, an altered growth rate inside the biofilm, a stress response to unfavorable environmental conditions, and over-expression of genes [5]. 
PAPers in Physics, vol. 13, ARt. 130005 (2021) / M. M. Shawki et al.

The detrimental impacts of bacterial adhesions generate serious environmental problems, public health risks and, eventually, vast economic losses. Environmentally, biofilm in association with algae and other organisms disrupts the natural ecosystem by causing biofouling, microfouling, macrofouling and inorganic fouling, which ultimately affects water quality, causing alterations in taste, color, and odor [6]. Industrially, biofilm is responsible for biocorrosion of metal pipelines, blockage of filtration systems, oil spoilage, low durability of construction materials [7], and spoilage of food and dairy products [8]. Medically, biofilms can colonize medical devices such as prosthetic joint replacements and heart valves, pacemakers, intra-ventricular cardiac assist devices, urinary tract catheters, peritoneal dialysis catheters, central venous catheters, neurovascular shunts, synthetic vascular grafts and stents, artificial voice prostheses, and intrauterine devices [9]. It has been estimated that two-thirds of human bacterial infections may involve biofilms [6].

A combined treatment based on applying direct electric current (DC) along with low doses of antibiotics can increase the efficacy of antibiotics on biofilms: this is termed the bioelectric effect [10]. DC voltage generates radicals as a result of electrolysis of the medium, which is suggested as a principal factor in its effectiveness [11]. In addition, some reports describe enhanced efficacy due to improved antibiotic binding to biofilms [12], and enhanced biofilm detachment, since an external DC electrostatic force can increase the area of bacterial exposure to the antibiotics [13].

The use of DC without antibacterial agents to reduce biofilm formation may prevent biofilm formation on certain biotic and abiotic substrates. DC can increase the repulsive electrostatic forces between organisms and the adhesive surface [14]. In addition, DC can reduce biofilm formation by changing physical conditions (e.g., temperature, $\mathrm{pH})$ at the adhesive surface, and through the accumulation of products of oxidative stress [15]. Previous studies have demonstrated that DC exhibits bactericidal activity against established biofilms $[16,17]$. This has the potential benefit of eliminating the use of traditional antimicrobials, thus decreasing the risk of selective resistance to these agents [18].

Nanoparticles (NPs) exhibit excellent antimicro- bial activities [19, 20] and are already being used in many commercial products, including toothpaste, sunscreen, and food products [21,22]. NPs are considered a promising tool for the treatment of bacterial biofilms because antibiotic resistance mechanisms are not effective against them. NPs can enter a biofilm system, settle on its surfaces and migrate to its inner portion [23]. They then interact with microbes and EPS and can subsequently reduce microbial activities and alter population structure pollutants [24]. Of all the NPs, the most promising and widely studied are metal oxides, such as $\mathrm{TiO}_{2}$ [25]. $\mathrm{TiO}_{2}$-NPs have excellent antimicrobial activity and constitute one of the most extensively manufactured and used nanomaterials, with a global production of 5500 tons per year [26]. $\mathrm{TiO}_{2}-\mathrm{NPs}$ are commonly used in paints, pigments, food, cosmetics, coatings, paper, catalysts, and plastics $[27,28]$. They can inhibit bacterial growth and biofilm formation [29], and have excellent antimicrobial effects on biofilm formation and the chronic toxicity of mature biofilms [30].

However, the continuous release of metal oxide ions such as $\mathrm{TiO}_{2}$ from $\mathrm{TiO}_{2}$-NPs causes massive production of oxygen free radicals or reactive oxygen species (ROS). The smaller particle size of $\mathrm{TiO}_{2}-\mathrm{NPs}$ allows them to pass through the EPS matrix of the biofilm and enter the cells through porins, water-filled channels that aid the process of exchange/transport of low molecular weight compounds with the ambient environment. When NPs enter the cytoplasm they have an even more destructive effect on metabolism and biochemical activities, particularly respiration and subsequent energy-dependent cellular processes [31]. NPs bind mainly to - $\mathrm{SH}$ groups of amino acids and formations of extra -S-S- bonds. The resulting conformational changes in protein structure lead to protein inactivation and ribosome denaturation [32]. In this way enzymes in the respiratory chain are deactivated; this is followed by the obstruction of electron transport by oxygen and finally by blockage of ADP-phosphorylation to ATP. At a genetic level, $\mathrm{TiO}_{2}$-NPs bind to nucleic acids, blocking DNA replication and repair processes [33]. Also reported has been a lower ability of $P$. aeruginosa PAO1 to assimilate and transport iron and phosphorous, and inhibition of the biosynthesis and degradation of heme (Fe-S cluster) groups [34].

The present study aims to compare the effect of 

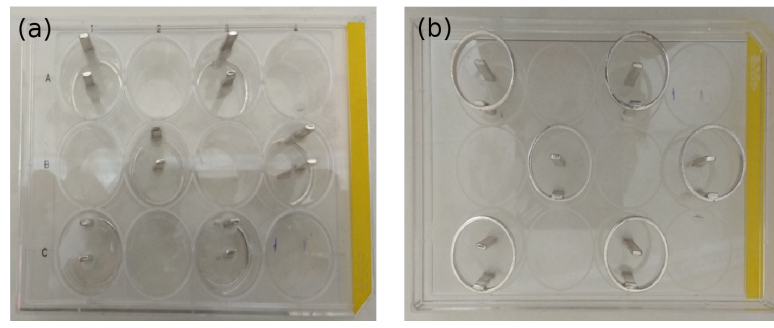

Figure 1: (a) Overhead view of the electrodes. (b) Inverted view of the electrodes.

different $\mathrm{TiO}_{2}-\mathrm{NP}$ concentrations with the effect of different low DC conditions on the biofilms of Bacillus cereus and Pseudomonas aeruginosa as models of Gram-positive and Gram-negative bacterial biofilms.

\section{Materials and methods}

\section{i $\quad \mathrm{TiO}_{2}$-NPs}

The $\mathrm{TiO}_{2}$-NPs (Aeroxide $\mathrm{R}$ ) $\mathrm{TiO}_{2} \mathrm{P} 25$ ) were purchased from Sigma Aldrich Inc., USA. $\mathrm{TiO}_{2}$ is composed of anatase $(85 \%)$ and rutile $(15 \%)$ crystal structure; the mean diameter of the Nano- $\mathrm{TiO}_{2}$ particles is $21 \mathrm{~nm}$. Nanoparticles were supplied as white nano-powder of hydrophilic fumed titanium dioxide nano-particles.

\section{ii Characterization of $\mathrm{TiO}_{2}-\mathrm{NPs}$}

$\mathrm{TiO}_{2}$-NPs were characterized by TEM, SEM, XRD, and FTIR [35,36]. The surface morphology and diameter of the nanoparticles were measured using TEM and SEM (ZEISS, Germany). The Xray diffraction (XRD) patterns of the samples were characterized using an X-ray diffractometer with $\mathrm{Cu}-\mathrm{K} \alpha$ radiation. The crystalline nature of the $\mathrm{TiO}_{2}$-NPs was recorded using X-ray diffraction (XRD) (Bruker, Germany) with $\mathrm{CuK} \alpha$ radiation $(1.5406 \AA)$ in the $2 \theta$ scan range of $10-90^{\circ}$. The FTIR spectrum of $\mathrm{TiO}_{2}$-NPs was recorded on Fourier Transform Infrared Spectrophotometer (Bruker, Germany) in the region of 4000 to 500 $\mathrm{cm}^{-1}$.

\section{iii DC exposure system}

A DC power supply (Etommens eTM-305A, made in China) was used to deliver $9 \mathrm{~V}, 6 \mathrm{~mA}$ direct electric current. The electric current was applied through a pair of silver/silver chloride electrodes. The anode is designed in the form of two connected pieces. The lower part is a circle of $1 \mathrm{~cm}$ radius, while the upper part is a long plate. The diameter of the circle part is designed to fit the diameter of the well of the 12-well polystyrene microtitre. The cathode is a long rod plate placed at a distance of 1 $\mathrm{cm}$ from the anode. Both cathode and anode rods were fixed to two holes in the lid of a cover of the microtitre plate. These electrodes were repeated to face each well in the microtitre plate. Figure 1 illustrates an image of the electrodes: Fig. 1(a) is an overhead view while Fig. 1(b) is an inverted view.

\section{iv Antibiofilm potential of $\mathrm{TiO}_{2}-\mathrm{NPs}_{\mathrm{s}}$ and DC in the eradication of established biofilm}

\section{a Biofilm Formation}

$B$. cereus and $P$. aeruginosa were examined as models for Gram-positive and Gram-negative bacteria, respectively. Initially, $3 \mathrm{~mL}$ of tryptone soy broth (TSB), supplemented with $1 \%$ glucose-containing $10^{8} \mathrm{CFU} / \mathrm{mL}$ (0.5 McFarland) of each bacterial culture, was put into a 12 -well polystyrene microtitre plate, and TSB was incorporated as a negative control. The plate was incubated for $24 \mathrm{~h}$ under aerobic static incubation at $37^{\circ} \mathrm{C}$ to allow the formation of a multilayer biofilm. After incubation, the planktonic non-adherent cells were blotted out and each well washed three successive times with $3 \mathrm{ml}$ of physiological saline solution.

\section{$b \quad$ Application of $\mathrm{TiO}_{2}-\mathrm{NPs}$ and $\mathrm{DC}$ to the biofilms}

The preformed biofilms were suspended in $3 \mathrm{~mL}$ of fresh TSB and exposed to different treatments (electricity or $\mathrm{TiO}_{2}-\mathrm{NPs}$ ). In the $\mathrm{TiO}_{2}-\mathrm{NP}$ exposure groups $200 \mu \mathrm{L}$ of various concentrations of $\mathrm{TiO}_{2}-\mathrm{NPs}$, ranging from 5 to $160 \mu \mathrm{g} / \mathrm{mL}$, were added to each well and incubated as mentioned previously. In the DC exposure groups DC was applied to three groups of each biofilm type for 5 , 10 , and $15 \mathrm{~min}$ respectively. The electrical energies 


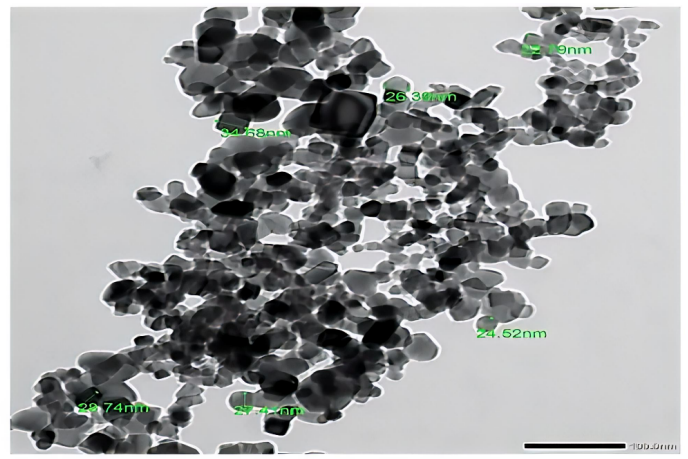

Figure 2: Transmission electron microscopy of $\mathrm{TiO}_{2}$ NPs ( JEM-1400 Plus, SA-MAG X 50k).

used were therefore $16.2 \mathrm{~J}, 32.4 \mathrm{~J}$, and $48.6 \mathrm{~J}$, respectively. Temperature was measured every $5 \mathrm{~min}$ using a digital thermometer. After incubation the adhered bacterial slimes were quantified using $0.3 \%$ crystal violet (CV) solution. The dye attached to the surface-adhered cells was solubilized with acetic acid $(33 \%)$ and determined spectrophotometrically at $590 \mathrm{~nm}$ (Tecan Infinite M200, Switzerland). The eradication percentage of the biofilms was calculated by the following equation [37]:

$$
\text { Eradication } \% \text { of the biofilms }=100 \frac{A-A_{0}}{A} .
$$

Where $A$ represents the absorbance of the untreated control wells and $A_{0}$ the absorbance of the treated wells. All the experiments were performed in triplicate, and the following methods were used to evaluate the effect of each protocol applied to each biofilm type.

\section{v Exopolysaccharide (EPS) and protein content assessment}

For determination of the exopolysaccharide (EPS) content of detached biofilms, the decanted cell-free supernatant was added to three volumes of ice-cold absolute ethanol and incubated overnight at $4{ }^{\circ} \mathrm{C}$. The resulting pellets were centrifuged, dried and their yield was assessed using the phenol-sulfuric acid approach. Briefly, $0.1 \mathrm{~mL}$ of EPS samples were mixed with $1.0 \mathrm{~mL}$ of cold phenol $(6 \%)$ and $5.0 \mathrm{~mL}$ of sulfuric acid $95 \%(\mathrm{v} / \mathrm{v})$; the mixture was shaken and incubated for $10 \mathrm{~min}$. Absorbance was measured at $490 \mathrm{~nm}$. The EPS content of each sample was calculated using the glucose standard curve [38]. Protein content was also determined [39]. Based on the Bradford method, we mixed well $100 \mu \mathrm{L}$ of detached biofilms with $5 \mathrm{~mL}$ Bradford solution (100 mg Coomassie Brilliant Blue G250 was dissolved in $50 \mathrm{~mL} \mathrm{95 \%} \mathrm{ethanol,} \mathrm{then} 100$ $\mathrm{mL}$ of $85 \%$ phosphoric acid $\left(\mathrm{H}_{3} \mathrm{PO}_{4}\right)$ was carefully mixed in by stirring, completing to $1 \mathrm{~L}$ total volume). After 5 min incubation at room temperature, absorbance was measured at $595 \mathrm{~nm}$. A standard curve was constructed by BSA (0, 0.0625, 0.125, $0.25,0.5$ and $1 \mathrm{~g} / \mathrm{L})$.

\section{vi Cell surface hydrophobicity evaluation}

The cell surface hydrophobicity (CSH) of the bacterial cultures, control and treated, was determined. The bacterial cells in detached biofilms were harvested by centrifugation at $12000 \mathrm{rpm}$ for 10 min, and the pellets obtained washed twice with sterile PBS. The bacterial suspensions were vortexed vigorously with an equal volume of hydrocarbon (e.g., xylene), held at room temperature for $5 \mathrm{~min}$. The absorbance of the aqueous phase was determined spectrophotometrically at $600 \mathrm{~nm}$ (Labomed. model UV-Vis Double beam spectrophotometer) [40].

\section{vii Reactive oxygen species assay}

The reactive oxygen species (ROS) produced by the bacterial cells as a result of the different treatments with electricity and NPs were evaluated by FDA, 3,6-diacetoxyfluoran assay. Briefly, $100 \mu \mathrm{L}$ of FDA $(10 \mu \mathrm{g} / \mathrm{mL})$ was added to each treated sample and control, then incubated for $30 \mathrm{~min}$ at $30{ }^{\circ} \mathrm{C}$. After incubation, cleavage of the FDA was stopped by the addition of acetone to a final concentration of $50 \% \mathrm{v} / \mathrm{v}$. To eliminate suspended particles, the mixture was centrifuged for $5 \mathrm{~min}$ at $10000 \mathrm{rpm}$. Fluorescence intensity was analyzed by a fluorimeter microplate reader (FluoStar Omega, Germany) with excitation and an emission wavelength of 495 $\mathrm{nm}$ and $525 \mathrm{~nm}$, respectively. ROS concentration was determined by the standard curve of $\mathrm{H}_{2} \mathrm{O}_{2}$ at different concentrations [41]. 


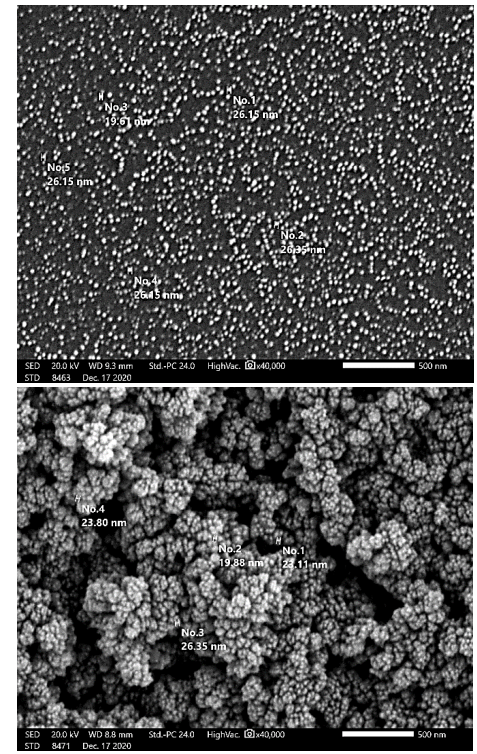

Figure 3: Examples of scanning electron microscopy images of $\mathrm{TiO}_{2}-\mathrm{NPs}$

\section{viii Study of morphological changes in biofilm using SEM}

The influence of different treatments on biofilm disintegration was visualized by scanning electron microscopy. Biofilms were grown on glass coverslips $(11 \mathrm{~mm})$ submerged in a 12 -well polystyrene microtitre plate containing $10^{8} \mathrm{CFU} / \mathrm{mL}$ both in the control and treated wells. After incubation, the coverslips were gently washed with $0.85 \% \mathrm{NaCl}$ to remove planktonic cells. Samples were fixed in $2.5 \%$ buffered glutaraldehyde for $24 \mathrm{~h}$, followed by washing with $4 \%$ OsO4 in $0.1 \mathrm{M}$ phosphate buffer for $2 \mathrm{~h}$ [42]. Samples were dehydrated with a gradient acetone series (35-100\%) for $15 \mathrm{~min}$. The dried biofilms were coated with gold and visualized under SEM (JEOL JSM 6360LA, Japan).

\section{ix Statistical analysis}

All data were expressed as the mean \pm standard deviation (SD) of three independent repeats. ANOVA was used to evaluate the difference between multiple groups. Significant differences between experimental groups were determined using a two-tailed Student's t-test (Excel 2013 Microsoft, USA). Results were considered statistically significant when

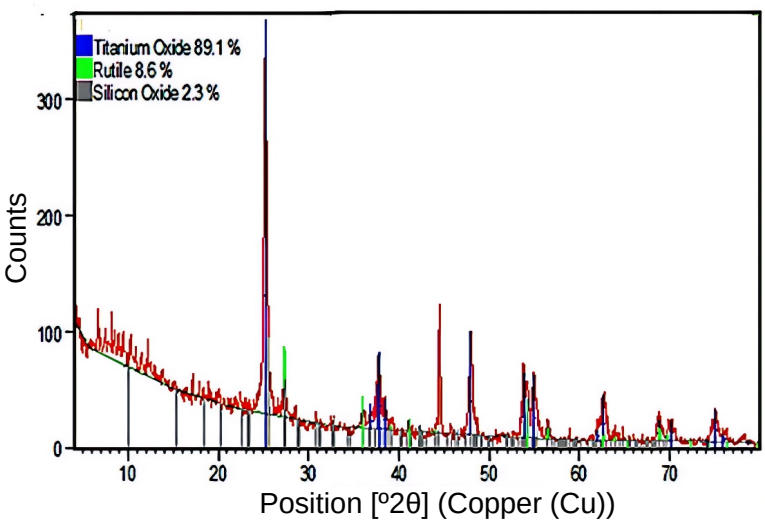

Figure 4: X-Ray Diffraction of $\mathrm{TiO}_{2}-\mathrm{NPs}$.

the p-value $<0.05$

\section{Results}

\section{i Characterization of $\mathrm{TiO}_{2}-\mathrm{NPs}$}

The transmission electron micrographs of $\mathrm{TiO}_{2}-$ NPs in Fig. 2 show the relatively narrow dispersion characteristic and spherical morphology of NPs with diameters of 22-34 nm. The morphology and size of the NPs were characterized using scanning electron microscopy (SEM). Agglomerating and roughly spherical NPs are illustrated using SEM images in Fig. 3.

To confirm the presence of $\mathrm{TiO}_{2}$ and analyze the structure, we used a powdered sample and a $\mathrm{CuK} \alpha$ - X-Ray Diffractometer: results are shown in Fig. 4. The peaks appeared at $2 \theta$ value ranging the diffraction peak at $2 \theta$ with $25^{\circ}, 38^{\circ}, 48^{\circ}, 54^{\circ}, 62^{\circ}$, corresponds to the crystal planes of (101), (004), (200), (105) and (204) respectively, indicating the formation of the anatase phase of $\mathrm{TiO}_{2}$ [43].

FTIR analysis was used to determine the functional groups of $\mathrm{TiO}_{2}$-NPs. Figure 5 shows the FTIR spectrum of $\mathrm{TiO}_{2}-\mathrm{NPs}$, in which the peaks at $3351.69 \mathrm{~cm}^{-1}$ and $1635.82 \mathrm{~cm}^{-1}$ are due to the stretching and bending vibration of the $-\mathrm{OH}$ group. The peaks at $2853.18 \mathrm{~cm}^{-1}$ and 2921.78 $\mathrm{cm}^{-1}$ are attributed to the $\mathrm{C}-\mathrm{H}$ stretching bands, which means there is a trace of organic compounds. The peak at $1466.82 \mathrm{~cm}^{-1}$ is related to Ti-O modes. The formation of bands below $800 \mathrm{~cm}^{-1}$ corresponds to the formation of titanate; i.e., the de- 


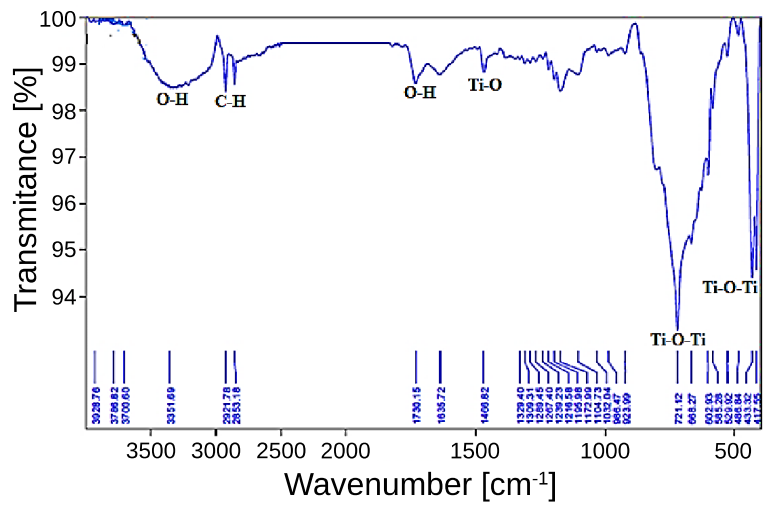

Figure 5: FTIR of $\mathrm{TiO}_{2}-\mathrm{NPs}$.

sired phase, so the peaks at $433.32 \mathrm{~cm}^{-1}$ and from $486.84 \mathrm{~cm}^{-1}$ to $721.12 \mathrm{~cm}^{-1}$ show the bending and stretching mode of Ti-O-Ti. These bands are in agreement with those reported previously $[43,44]$.

\section{ii Antibiofilm potential of $\mathrm{TiO}_{2}-\mathrm{NPs}$ and DC for eradication of established biofilm}

Firstly, the effect of both treatments in the eradication of preformed biofilms was determined as shown in Fig. 6. The results indicate a significant reduction in biofilm adherence due to either $\mathrm{TiO}_{2}-\mathrm{NPs}$ or DC. The eradication potency increases significantly as $\mathrm{TiO}_{2}-\mathrm{NP}$ concentrations increase, showing dose-dependent behavior. The antibiofilm activity caused by $\mathrm{TiO}_{2}$-NPs ranged from $1 \%$ at 5 $\mu \mathrm{g} / \mathrm{mL}$ to $75 \%$ at $160 \mu \mathrm{g} / \mathrm{mL}$ in the case of $B$. cereus, whereas at the same concentrations in $P$.

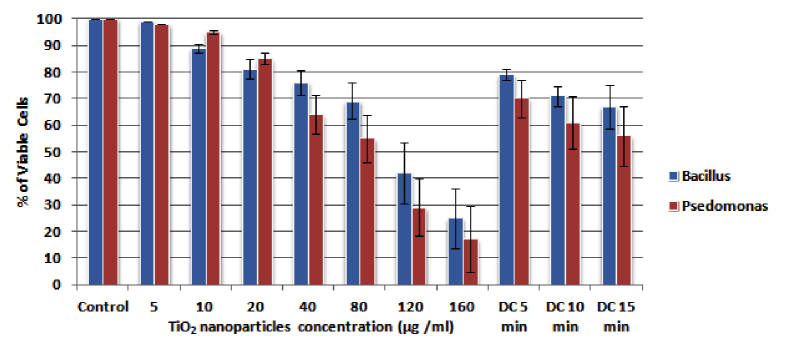

Figure 6: The effect of $\mathrm{TiO}_{2}-\mathrm{NP}$ concentrations (5-160 $\mu \mathrm{g} / \mathrm{mL}$ ) and DC exposure (5, 10, and $15 \mathrm{~min}$ ) on the percentage of viable cells of $B$. cereus and $P$. aeruginosa biofilms. aeruginosa biofilm it ranged from $2 \%$ to $83 \%$. The LD50 calculated for B. cereus is $104 \pm 4 \mu \mathrm{g} / \mathrm{mL}$ while for $P$. aeruginosa it is $63 \pm 3 \mu \mathrm{g} / \mathrm{mL}$. Regarding DC energy, as the DC exposure time (energy) increased, the disintegration percent significantly increased. It reached $21 \%, 29 \%$, and $33 \%$ at exposure time 5-, 10-, and 15-min, respectively for B. cereus and $30 \%, 39 \%$, and $44 \%$ respectively for P. aeruginosa. The effect of DC exposure for 15 $\mathrm{min}$ is thus considered equivalent to the effect of 40 $\mu \mathrm{g} / \mathrm{mL} \mathrm{TiO}_{2}$-NPs. In addition, the EPS and protein concentrations in the decanted bacterial cultures increased under both treatments, reflecting biofilm destabilization and detachment. The results of EPS and protein concentrations support the results of the eradication percentage, as shown in Figs. 7 and 8. Notably, compared to the control treatment there was a small increase of $1.2 \pm 0.2{ }^{\circ} \mathrm{C}$ in temperature after $15 \mathrm{~min}$ of $\mathrm{DC}$ exposure. Temperature change is therefore not an effective factor in this work.

\section{iii Cell surface hydrophobicity (CSH) eval- uation}

Bacterial treatments that exhibited a $\mathrm{CSH} \%$ lower than $30 \%$ were deemed hydrophilic, and those with CSH higher than $70 \%$ were considered hydrophobic; samples with CSH between $30 \%$ and $70 \%$ were categorized as moderately hydrophobic [45]. As shown in Fig. 9, control biofilms and biofilms treated with $5 \mu \mathrm{g} / \mathrm{mL} \mathrm{TiO}_{2}$-NPs are hydrophobic. Biofilms treated with $10-160 \mu \mathrm{g} / \mathrm{mL}$ became moderately hydrophobic. As the concentration increased, the degree of CSH decreased. Biofilms ex-

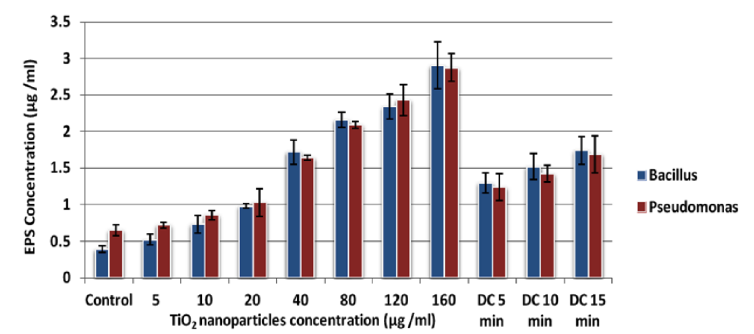

Figure 7: The effect of $\mathrm{TiO}_{2}-\mathrm{NP}$ concentrations (5-160 $\mu \mathrm{g} / \mathrm{mL}$ ) and DC exposure (5, 10, and $15 \mathrm{~min})$ on the EPS concentration $(\mu \mathrm{g} / \mathrm{mL})$ of B. cereus and P. aeruginosa biofilms. 


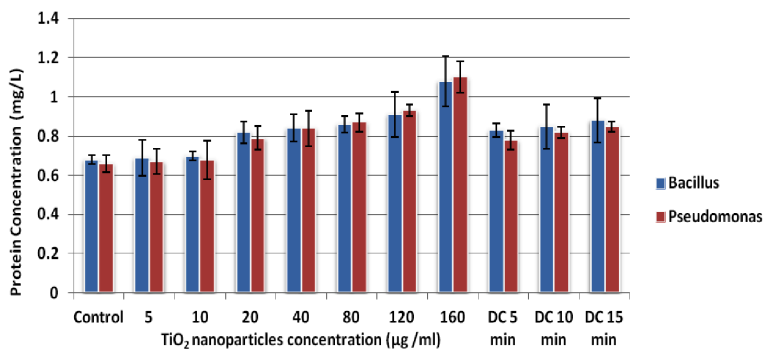

Figure 8: The effect of $\mathrm{TiO}_{2}-\mathrm{NP}$ concentrations (5$160 \mu \mathrm{g} / \mathrm{mL}$ ) and $\mathrm{DC}$ exposure $(5,10$, and $15 \mathrm{~min})$ on the protein concentration $(\mathrm{mg} / \mathrm{L})$ of $B$. cereus and $P$. aeruginosa biofilms.

posed to DC also became moderately hydrophobic. As the DC energy increased, the CSH \% decreased. Exposure to DC for 15 min affected hydrophobicity by a percentage close to that generated by 40 $\mu \mathrm{g} / \mathrm{mL} \mathrm{TiO}_{2}-\mathrm{NPs}$, in both biofilm types.

\section{iv Determination of reactive oxygen species (ROS)}

ROS are one of the factors most lethal to biofilms. As ROS concentration increases, their chance of survival decreases. There is a significant increase in ROS concentration with the increase in $\mathrm{TiO}_{2}{ }^{-}$ NPs concentrations and DC energy, as shown in Fig. 10. The amount of ROS produced due to DC exposure (5-15 $\mathrm{min})$ is similar to the concentration produced by $20-40 \mu \mathrm{g} / \mathrm{mL} \mathrm{TiO}_{2}-\mathrm{NPs}_{\text {s }}$

\section{$v$ Study of morphological changes in biofilm before and after treatments}

The use in this work of complementary microscopic means, such as SEM, enhanced visualization of morphological changes brought about by DC and NPs in the architectural properties of the mature preformed biofilms (B. cereus and $P$. aeruginosa biofilms), including cell surface, cell shape, cell distribution inside the EPS matrix, adhesion areas, and detachment. As depicted in Fig. 11, the mature biofilm morphology and structure seemed to be unique for each biofilm type examined. Both types of biofilm appeared healthy, exhibiting normal rod cell shape with average dimensions: $1 \pm 0.2$, $1.5 \pm 0.4 \mu \mathrm{m}$ length and $0.41 \pm 0.05,0.2 \pm 0.05$ $\mu \mathrm{m}$ width for $B$. cereus and $P$. aeruginosa biofilms,

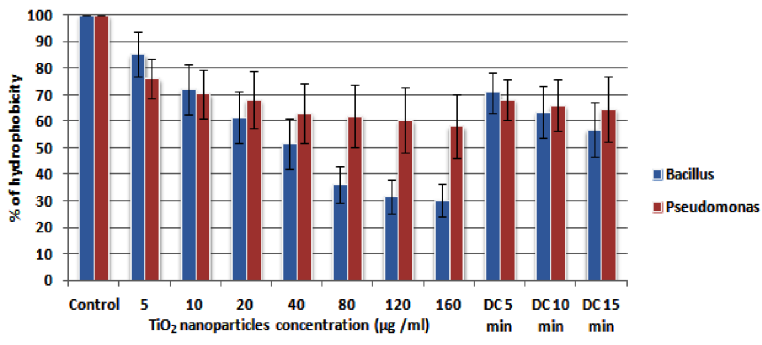

Figure 9: The effect of $\mathrm{TiO}_{2}-\mathrm{NP}$ concentrations (5-160 $\mu \mathrm{g} / \mathrm{mL})$ and DC exposure $(5,10$, and $15 \mathrm{~min})$ on the hydrophobicity percentage of $B$. cereus and $P$. aeruginosa biofilms.

respectively (Figs. 11-A and 11-D). However, $B$. cereus cells were homogeneously distributed over the surface and fully wrapped in a dense, mucilaginous, stringy-like matrix of EPS (indicated by black arrows). On the other hand, P. aeruginosa cells were massive, compacted, smooth, aligned, tightly packed, and aggregated on an amorphous matrix. The SEM micrographs showed no significant alterations in overall size or cell surface following the DC and NP treatments, although there was obvious destruction of the biofilm structure. By applying DC with $9 \mathrm{~V}$ and $6 \mathrm{~mA}$ for $15 \mathrm{~min}$, moderate damage was observed in $B$. cereus biofilm. The majority of the cells retained the same normal shape with a lower number of cells individualized in less dense EPS matrix (Fig. 11-B). In addition, some cells were dramatically distorted, with clear furrows (indicated by red arrows); this implies disruption of the membranes of the bacterial cells

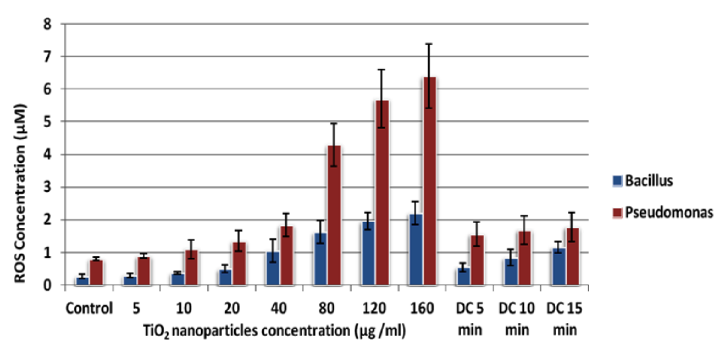

Figure 10: The effect of $\mathrm{TiO}_{2}-\mathrm{NP}$ concentrations (5-160 $\mu \mathrm{g} / \mathrm{mL})$ and $\mathrm{DC}$ exposure $(5,10$, and $15 \mathrm{~min})$ on the ROS concentration $(\mu \mathrm{M})$ of B. cereus and P. aeruginosa biofilms. 


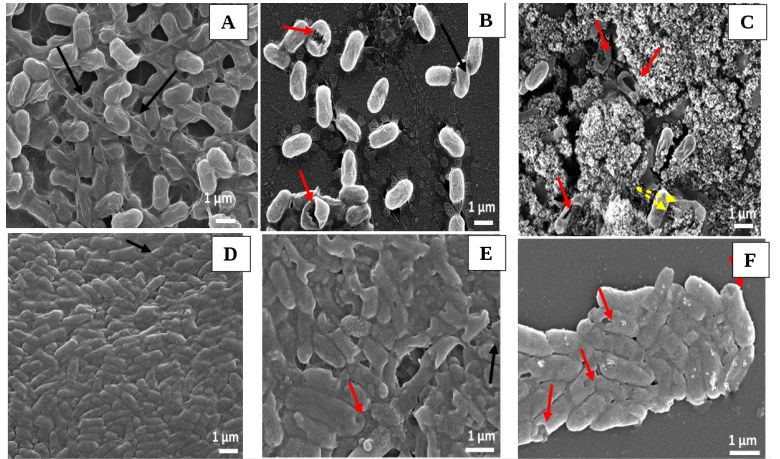

Figure 11: Scanning electron micrograph of B. cereus and $P$. aeruginosa biofilms before and after DC and $\mathrm{TiO}_{2}$-NP exposure. (A) control biofilm of B. cereus, (B) DC-treated $B$. cereus biofilm, (C) $\mathrm{TiO}_{2}-\mathrm{NPs}^{-}$ treated B. cereus biofilm, (D) control biofilm of $P$. aeruginosa, (E) DC-treated $P$. aeruginosa biofilm, (F) $\mathrm{TiO}_{2}-\mathrm{NPs}$-treated $P$. aeruginosa biofilm. (Black arrows indicate EPS matrix, red arrows, furrows in damaged cells and yellow dashed arrows, indentations).

and further leakage of cellular cytoplasmic fluid, as recorded by Krishnamurthi et al., 2020 [45]. In contrast, relatively potent biofilm destruction was displayed by $P$. aeruginosa biofilm (Fig. 11-E). As shown, severe deformation was observed in the cell debris that still adhered to the slimy matrix. Our results are consistent with the earlier finding of Luo et al., 2005 [46]. Regarding $\mathrm{TiO}_{2}$-NPs treatment, Fig. 11-C illustrates aggregations of $\mathrm{TiO}_{2}-\mathrm{NPs}$ absorbed on the EPS-matrix of B. cereus biofilm. Additionally, some cells appeared separate from each other, seemingly deformed by the presence of large furrows and small indentations (dashed yellow arrow). Similarly, Horst et al., 2010 [47] recorded the agglomeration behavior of $\mathrm{TiO}_{2}$-NPs on biofilm surface. Cell density markedly diminished with the damaged morphology (furrows and pits) of $P$. aeruginosa biofilm exposed to $\mathrm{TiO}_{2}$-NPs (Fig. 11F).

\section{Discussion}

Some studies have found that electrical current alone does not result in microbial death; however, other studies have reported some effect when applied to biofilms. Poortinga et al. [48] reported electrical detachment of biofilm formations from surgical implants, while Van der Borden et al. [49] demonstrated that DC of only $25-125 \mathrm{~mA}$ can stimulate detachment of staphylococcal strains from stainless steel, Moreover, Del Pozo et al. [14] recorded a decrease in the viability of $S$. aureus, S. epidermidis and P. aeruginosa biofilms after prolonged exposure to a low-intensity electrical current of 20-2000 mA. On the other hand, Jass et al. [50] reported that electric currents of up to $20 \mathrm{~mA} / \mathrm{cm}^{2}$ delivered for 12 hours did not prevent biofilm formation or have any detrimental effect on an established biofilm.

Biofilm formation can be reduced using lowintensity DC, but further investigation is needed to determine the appropriate dose and time of administration. The effectiveness of electric current in inhibition of growth and mortality is directly related to increasing microamperage [51]. The high sensitivity of Gram-negative bacteria to electric current was confirmed by Davis et al. [52], who found that both E. coli and Salmonella typhimurium were inhibited and killed by low microamperage; they also reported that $E$. coli is more negatively sensitive to increasing current intensity than $B$. cereus. Our results support the theory that Gram-negative bacteria ( $P$. aeruginosa) are more sensitive to low DC than Gram-positive bacteria (B. cereus), with a difference of $9-11 \%$ for $5-15$ min of exposure. This higher sensitivity is not only to DC but also to $\mathrm{TiO}_{2}$-NPs: The concentration of $\mathrm{TiO}_{2}$-NPs required to cause LD50 is lower for $P$. aeruginosa (63 $\pm 3 \mu \mathrm{g} / \mathrm{mL})$ than for B. cereus $(104 \pm 4 \mu \mathrm{g} / \mathrm{mL})$.

The development of biofilm-related infections begins with adhesion of the microorganism to the biomaterial surface, mediated by Van der Waals forces, acid-base interactions, and electrostatic forces [53]. The electrostatic force between bacteria and the biomaterial is generally repulsive, since almost all biomaterial surfaces are negatively charged, as are bacterial cells [54]. It has been proposed that repulsive forces can be enhanced by the application of electric current, provoking surface detachment of bacterial biofilms [55]. When a biofilm-covered steel slide was connected as the anode in an electrical circuit with a $6 \mathrm{~V}$ potential, biofilm rapidly sloughed from the surface [17]. DC alone had a lethal effect on both biofilms in our study: $33 \%$ for B. cereus and $44 \%$ for P. aeruginosa after $15 \mathrm{~min}$ of DC exposure.

It has been proposed that the direct damage- 
Papers in Physics, vol. 13, ART. 130005 (2021) / M. M. Shawki et al.

caused to biofilms by DC is by electroporation and/or production of ROS, as well as the generation of other toxic substances such as Chlorine [11]. The effects of electrical currents on S. epidermidis biofilms were interpreted by considering the electrolytic reactions occurring: it was hypothesized that an increase in $\mathrm{pH}$ near the anode leads to alkaline hydrolysis of the polysaccharide matrix of the biofilm [17]. Our results show that significantly more ROS is produced in the DC-treated groups than in the control, for both biofilms.

Summarily, the substantial biocidal mechanism induced by DC is production of $\mathrm{ROS}$ (e.g., $\mathrm{H}_{2} \mathrm{O}_{2}$, chlorine molecules, etc.) as a result of electrolysis. This triggers enzyme oxidation and membrane puncturing, which leads to leakage of cytosolic constituents and a reduction in respiration rate [16]. The DC had an indirect effect with prolonged time of exposure, through temperature and $\mathrm{pH}$. This liberated, accelarated and oriented the charges/electron in the electrical field toward negatively charged EPS. In turn, this impaired the biofilm matrix stabilization, altered the surface charge, reduced hydrophobicity, perturbed bacterial membrane integrity, increased membrane permeability and increased ROS [56,57]. All these destructive effects were emphasized in Figs. 7, 8, 9, 10 , and 11 .

In the current study, the ability of $\mathrm{TiO}_{2}$-NPs to disintegrate the biofilm established by $B$. cereus and $P$. aeruginosa was exerted through this multidisruptive mechanism. It began mainly by disrupting and destabilizing the protective matrix (extracellular polymeric substances) containing mostly EPS and protein. This appears clearly in Figs. 7 and 8, and also in the reduction of hydrophobicity property as shown in Fig. 9, where a higher concentration of unattached EPS and protein content was eliminated when the concentration of $\mathrm{TiO}_{2}{ }^{-}$ NPs was increased. Similarly, in the same context, hydrophobicity decreased with an increase in the treatment dose. The significant relationship between cell surface hydrophobicity and biofilm formation, which is closely linked to the EPS matrix secreted by the biofilm $[58,59]$, is worthy of mention. In line with our results, Mu et al., (2021) [60] found that powerful treatment with antibiofilm agents caused a decrease in S. epidermidis biofilm attachment, and consequently decreased cell surface hydrophobicity via attenuation of EPS forma- tion. Once $\mathrm{TiO}_{2}-\mathrm{NPs}$ have disturbed the EPS matrix, they enter the cells via porin channels and continue to damage them. Figures 10 and 11 support this. As $\mathrm{TiO}_{2}$-NPs were increased, the oxidative stress triggered by ROS increased. Additionally, the morphological changes caused by the $\mathrm{TiO}_{2}-\mathrm{NPs}$, in the form of cell deformation and decreasing EPS content, were observed clearly by SEM (Fig. 11). All this evidence affirms the antagonistic activity of $\mathrm{TiO}_{2}-\mathrm{NPs}_{\mathrm{s}} \mathrm{TiO}_{2}-\mathrm{NPs}$ show antibacterial properties against Gram-positive and Gram-negative bacteria (7-8 nm), the latter being the more sensitive. This could be related to the fact that Gram-positive bacteria have a thicker layer of peptidoglycan (20-80 nm) than Gram-negative bacteria, which facilitates the absorption of reactive radicals, thereby preventing cell damage from radical attack $[31,34]$.

$\mathrm{TiO}_{2}-\mathrm{NPs}_{\mathrm{s}}$ can reduce the adhesion of bacteria and inhibit biofilms. Exposure to $\mathrm{TiO}_{2}-\mathrm{NPs}_{\mathrm{s}}$ leads to the destruction of bacteria inside the biofilm, primarily due to the generation of ROS and lipid oxidation on the cell wall membrane [61]. It has been shown that $\mathrm{TiO}_{2}-\mathrm{NPs}_{\mathrm{s}}$ are effective against biofilms of MRSA [62]. $\mathrm{TiO}_{2}$-NPs could control the growth and biofilm formation of S. mitis ATCC 6249 and Ora-20, and can be used in oral hygiene. $\mathrm{TiO}_{2}{ }^{-}$ NPs have a low impact on $P$. aeruginosa biofilms at $31.25 \mu \mathrm{g} / \mathrm{mL}$ concentration and disrupt previously established biofilms in the microtiter plate [63]. In the presence of $\mathrm{TiO}_{2}$-NPs, the biofilm formation of E. coli and B. subtilis was reduced by 40-50\% respectively [64]. However, $\mathrm{TiO}_{2}-\mathrm{NPs}_{\mathrm{S}}$ did not show significant bactericidal properties against certain types of drug-resistant bacteria which have a remarkable ability to withstand ROS membrane damage through over-expression of protective components and membrane repair elements [65]. Our results indicate that there is a significant increase in ROS production in groups exposed to $20 \mu \mathrm{g} / \mathrm{mL}$ or more, and this effect increases as $\mathrm{TiO}_{2}-\mathrm{NP}$ concentration increases.

Hydrophobic interactions in bacteria are one of the most important mechanisms for microbial attachment and aggregation, which are strongly associated with the protein secondary structures on the cell surfaces. The changes in the protein secondary structures on bacterial surfaces affected these hydrophobic interactions, which reduced the bacterial attachment ability [66]. The dynamic response 
PAPers in Physics, vol. 13, ART. 130005 (2021) / M. M. Shawki et al.

of a B. subtilis biofilm to temporary exposure to $\mathrm{TiO}_{2}$-NPs caused the dispersal of biofilm and bacteria after several hours of exposure, indicating that the changes in the cell/EPS surface structure and the decreased adhesive ability drove the biofilm dispersal [67]. Our current results show that the hydrophobicity of both biofilms is reduced by using either DC or $\mathrm{TiO}_{2}-\mathrm{NPs}$ of concentration $10 \mu \mathrm{g} / \mathrm{mL}$ or more.

In a previous study, $\mathrm{TiO}_{2}$-NPs showed lower inhibitory and biofilm concentration against $S$. $m u$ tans and $S$. sanguinis than NPs containing Ag NPs, $\mathrm{Fe}_{3} \mathrm{O}_{4}$ NPs, antibiotics, and chlorhexidine [68]. $\mathrm{TiO}_{2}$-NPs also exhibit marked antimicrobial and antibiofilm activity against ATCC 6249 and Ora-20 and hence can control their growth and biofilm formation in the oral cavity even at a concentration as low as $50 \mu \mathrm{g} / \mathrm{ml}$, due to disruption of the cell wall and oxidative stress [69], which are recorded also in the current study.

Generally, although the EPS-matrix represents the robust skeleton that protects the biofilm cells from stress, the eradication and detachment capacity of both DC and NPs were evident throughout the current study. This could be attributed to alterations in the physical-chemical characteristics of both biofilm and adherent surfaces (i.e., polymeric properties, hydrophobicity/hydrophilicity, charge, roughness, and surface free energies) induced by both treatments, which ultimately destabilized adhesion of the preformed biofilm to the surface $[70,71]$. Moreover, the involvement of water channels in the core structure of the biofilm, which allow mainly the transportation of nutrients, could permit the diffusion of toxic substances that generate ROS, which unambiguously cause cell damage [71-73]. This assumption was confirmed simultaneously via SEM (the presence of pores, pits, furrows, and cell deformation) and ROS results.

Interestingly, the absence of full inhibition and eradication of both biofilms by DC and NPs could be explained by the higher resistance of mature biofilm cells during the stationary phase, as reported by Rodrigues et al. [74]. Arguably, any antibiofilm treatment will exhibit higher potency when applied during the evolution of a biofilm than when applied to a mature preformed one. Microbial cells that are free-floating or at the early stages of colonization seem to be vulnerable and susceptible to any treatment, especially before formation of the EPS-barrier and the evolution of quorum sensing signals between colonized cells [75].

\section{Conclusions}

Our results indicate that both $\mathrm{DC}$ and $\mathrm{TiO}_{2}-\mathrm{NPs}_{\mathrm{S}}$ have a lethal effect on Gram-Positive and GramNegative bacterial biofilms. Gram-Negative bacterial biofilms are more sensitive to both DC and $\mathrm{TiO}_{2}$-NPs than the Gram-Positive ones. Applying DC of 16.2-48.6 J affects bacterial biofilms in a similar way of using $\mathrm{TiO}_{2}-\mathrm{NPs}$ of $20-40 \mu \mathrm{g} / \mathrm{mL}$ concentration. $\mathrm{TiO}_{2}-\mathrm{NP}$ concentrations higher than $40 \mu \mathrm{g} / \mathrm{mL}$ produce a significantly greater lethal effect than the DC conditions used on both biofilms. The lethal effect on biofilms was verified by EPS, protein content and cell surface hydrophobicity assessment, as well as scanning electron microscopy visualization. The mechanism of action was correlated with the ROS produced.

[1] R M Donlan, J W Costerton, Biofilms: Survival mechanisms of clinically relevant microorganisms, Clin. Microbiol. Rev. 15, 167 (2002).

[2] L E Chávez de Paz, A Resin, K A Howard, D S Sutherland, P L Wejse, Antimicrobial effect of chitosan nanoparticles on Streptococcus mutans biofilms, Appl. Environ. Microbiol. 77, 3892 (2011).

[3] H Anwar, M K Dasgupta, J W Costerton, Testing the susceptibility of bacteria in biofilms to antibacterial agents, Antimicrob. Agents Ch. 34, 2043 (1990).

[4] R M Donlan, Biofilms and device-associated infections, Emerg. Infect. Dis. 7, 277 (2001).

[5] J L Del Pozo, M S Rouse, R Patel, Bioelectric effect and bacterial biofilms. A systematic review, Int. J. Artif. Organs 31, 786 (2008).

[6] K Lewis, Riddle of biofilm resistance, Antimicrob. Agents Ch. 45, 999 (2001).

[7] V Vishwakarma, Impact of environmental biofilms: Industrial components and its remediation, J. Basic Microbiol. 60, 198 (2020). 
PAPers in Physics, vol. 13, ART. 130005 (2021) / M. M. Shawki et al.

[8] S H Abidi, S K Sherwani, T R Siddiqui, A Bashir, S U Kazmi, Drug resistance profile and biofilm forming potential of Pseudomonas aeruginosa isolated from contact lenses in Karachi-Pakistan, BMC Ophthalmol. 13, 57 (2013).

[9] J L Del Pozo, R Patel, The challenge of treating biofilm-associated bacterial infections, Clin. Pharmacol. Ther. 82, 204 (2007).

[10] S A Blenkinsopp, A E Khoury, J W Costerton, Electrical enhancement of biocide efficacy against Pseudomonas aeruginosa biofilms, Appl. Environ. Microbiol. 58, 3770 (1992).

[11] E L Sandvik, B R McLeod, A E Parker, P S Stewart, Direct electric current treatment under physiologic saline conditions kills Staphylococcus epidermidis biofilms via electrolytic generation of hypochlorous acid, PLoS ONE 8, e55118 (2013).

[12] Y Kim, S Subramanian, K Gerasopoulos, et al., Effect of electrical energy on the efficacy of biofilm treatment using the bioelectric effect, Npj Biofilms Microbiomes 15016, (2015).

[13] A J van der Borden, $\mathrm{H}$ van der Werf, $\mathrm{H} \mathrm{C}$ van der Mei, H J Busscher, Electric currentinduced detachment of Staphylococcus epidermidis biofilms from surgical stainless steel, Appl. Environ. Microbiol. 70, 6871 (2004).

[14] M E Shirtliff, A Bargmeyer, A K Camper, Assessment of the ability of the bioelectric effect to eliminate mixed-species biofilms, Appl. Environ. Microbiol. 71, 6379 (2005).

[15] J L Del Pozo, M S Rouse, J N Mandrekar, J M Steckelberg, R Patel, The electricidal effect: Reduction of Staphylococcus and Pseudomonas biofilms by prolonged exposure to low-intensity electrical current, Antimicrob. Agents Ch. 53, 41 (2009).

[16] M Ruiz-Ruigomez, J Badiola, S SchmidtMalan, et al., Direct electrical current reduces bacterial and yeast biofilm formation, Int. J. Bacteriol. 9727810, 1 (2016).
[17] C Rabinovitch, P S Stewart, Removal and inactivation of Staphylococcus epidermidis biofilms by electrolysis, App. Environ. Microbiol. 72, 6364 (2006).

[18] D Zituni, H Schütt-Gerowitt, M Kopp, et al., The growth of Staphylococcus aureus and Escherichia coli in low-direct current electric fields, Int. J. Oral Sci. 6, 7 (2014).

[19] P P Mahamuni-Badiger, P M Patil, et al., Biofilm formation to inhibition: Role of zinc oxide-based nanoparticles, Mater. Sci. Eng.: C. 108, 110319 (2020).

[20] V Iribarnegaray, N Navarro, L Robino, $\mathrm{P}$ Zunino, J Morales, P Scavone, Magnesiumdoped zinc oxide nanoparticles alter biofilm formation of Proteus mirabilis, NanomedicineUK 14, 1551 (2019).

[21] D M Berube, E M Searson, T S Morton, C L Cummings, Project on emerging nanotechnologies - Consumer product inventory evaluated, Nanotech. Law and Bus. 7, 152 (2010).

[22] F Piccinno, F Gottschalk, S Seeger, B Nowack, Industrial production quantities and uses of ten engineered nanomaterials in Europe and the world, J. Nanoparticle Res. 14, 1109 (2012).

[23] K Ikuma, A W Decho, B Lau, When nanoparticles meet biofilms-interactions guiding the environmental fate and accumulation of nanoparticles, Front. Microbiol. 6, 591 (2015).

[24] H Mu, X Zheng, Y Chen, H Chen, K. Liu, Response of anaerobic granular sludge to a shock load of zinc oxide nanoparticles during biological wastewater treatment, Environ. Sci. Technol. 46, 5997 (2012).

[25] A Besinis, T De Peralta, R Handy, The antibacterial effects of silver, titanium dioxide and silica dioxide nanoparticles compared to the dental disinfectant chlorhexidine on Streptococcus mutans using a suite of bioassays, Nanotoxicology 8, 1 (2014).

[26] A Kubacka, M Diez, D Rojo, et al., Understanding the antimicrobial mechanism 
PAPers in Physics, vol. 13, ART. 130005 (2021) / M. M. Shawki et al.

of $\mathrm{TiO}_{2}$-based nanocomposite films in a pathogenic bacterium, Sci. Rep. 4, 4134 (2014).

[27] Y Qin, X Guo, F Tou, H Pan, J Feng, J $\mathrm{Xu}, \mathrm{B}$ Chen, M Liu, Y Yang, Cytotoxicity of $\mathrm{TiO}_{2}$ nanoparticles toward Escherichia coli in an aquatic environment: Effects of nanoparticle structural oxygen deficiency and aqueous salinity, Environ. Sci. Nano. 4, 1178 (2017).

[28] P Westerhoff, G Song, K Hristovski, M A Kiser, Occurrence and removal of titanium at full scale wastewater treatment plants: Implications for $\mathrm{TiO}_{2}$ nanomaterials, J. Environ. Monitor 13, 1195 (2011).

[29] M A Maurer-Jones, I L Gunsolus, B M Meyer, C J Christenson, C L Haynes, Impact of $\mathrm{TiO}_{2}$ nanoparticles on growth, biofilm formation, and flavin secretion in Shewanella oneidensis, Anal. Chem. 85, 5810 (2013).

[30] L Shkodenko, I Kassirov, E Koshel, Metal oxide nanoparticles against bacterial biofilms: Perspectives and limitations, Microorganisms 8, 1545 (2020).

[31] S A Zaki, M M Eltarahony, D A Abd-ElHaleem, Disinfection of water and wastewater by biosynthesized magnetite and zerovalent iron nanoparticles via NAP-NAR enzymes of Proteus mirabilis 10B, Environ. Sci. Pollut. Res. 26, 23661 (2019).

[32] K S Khashan, G M Sulaiman, F A Abdulameer, S Albukhaty, M A Ibrahem, T AlMuhimeed, A A AlObaid, Antibacterial activity of $\mathrm{TiO}_{2}$ nanoparticles prepared by onestep laser ablation in liquid, App. Sci. 11, 4623 (2021).

[33] M Eltarahony, A Ibrahim, H El-Shall, E Ibrahim, F Althobaiti, E Fayad, Antibacterial, antifungal and antibiofilm activities of silver nanoparticles supported by crude bioactive metabolites of bionanofactories isolated from Lake Mariout, Molecules 26, 3027 (2021).

[34] C L de Dicastillo, M G Correa, F B Martínez, C Streitt, M J Galotto, Antimicrobial effect of titanium dioxide nanoparticles, In: Antimicrobial resistance - A one health perspective, Eds.
M Mares, S H E Lim, K S Lai, R-T Cristina, Pag. 95, IntechOpen, London (2020).

[35] S Bagheri, K Shameli, S Abd Hamid, Synthesis and characterization of anatase titanium dioxide nanoparticles using egg white solution via sol-gel method, J. Chem. 848205, 1 (2013).

[36] P Anandgaonker, G Kulkarni, S Gaikwad, A Rajbhoj, Synthesis of $\mathrm{TiO}_{2}$ nanoparticles by electrochemical method and their antibacterial application, Arab. J. Chem. 12, 1815 (2019).

[37] A Karunanidhi, E Ghaznavi-Rad, et al., Antibacterial and antibiofilm activities of nonpolar extracts of Allium stipitatum Regel. against multidrug resistant bacteria, Biomed. Res. Int. 11, 9845075 (2018).

[38] J Rajkumari, S Borkotoky, A Murali, S Busi, Anti-quorum sensing activity of Syzygium jambos (L.) Alston against Pseudomonas aeruginosa PAO1 and identification of its bioactive components, S. Afr. J. Bot. 118, 151 (2018).

[39] H K Maehre, L Dalheim, G K Edvinsen, E O Elvevoll, I J Jensen, Protein determination method matters, Foods 7, 5 (2018).

[40] C J L dos Ramos Almeida, S M da Silva, et al., Biofilm formation in Bacillus cereus, $B$. licheniformis and B. pumilus: An alternative for survival in impacted environments, Int. J. Sci. 6, 73 (2017).

[41] O Antonoglou, K Giannousi, et al., Elucidation of one step synthesis of PEGylated CuFe bimetallic nanoparticles. Antimicrobial activity of CuFe@PEG vs Cu@PEG, J. Inorg. Biochem. 177, 159 (2017).

[42] M Alavi, N Karimi, Antiplanktonic, antibiofilm, antiswarming motility and antiquorum sensing activities of green synthesized $A g-$ $\mathrm{TiO}_{2}, \mathrm{TiO}_{2}-\mathrm{Ag}, \mathrm{Ag}-\mathrm{Cu}$ and $\mathrm{Cu}-\mathrm{Ag}$ nanocomposites against multi-drug-resistant bacteria, Artif. Cell Nanomed. B. 46, S399 (2018).

[43] R SharmilaDevi, R Venckatesh, RajeshwariSivaraj, Synthesis of titanium dioxide nanoparticles by sol-gel technique, Int. J. Innovative Res. Sci. Eng. Tech. 3, 15206 (2014). 
PAPers in Physics, vol. 13, ART. 130005 (2021) / M. M. Shawki et al.

[44] A León, P Reuquen, C Garín, R Segura, P Vargas, P Zapata, P A Orihuela, FTIR and Raman characterization of $\mathrm{TiO}_{2}$ nanoparticles coated with polyethylene glycol as carrier for 2methoxyestradiol, Appl. Sci. 7, 49 (2017).

[45] V R Krishnamurthi, A Rogers, J Peifer, I I Niyonshuti, J Chen, Y Wang, Microampere electric current causes bacterial membrane damage and two-way leakage in a short period of time, Appl. Environ. Microbiol. 86, e01015 (2020).

[46] Q Luo, H Wang, X Zhang, Y Qian, Effect of direct electric current on the cell surface properties of phenol-degrading bacteria, Appl. Environ. Microbiol. 71, 423 (2005).

[47] A M Horst, A C Neal, R E Mielke, P R Sislian, W H Suh, L Mädler, G D Stucky, P A Holden, Dispersion of $\mathrm{TiO}_{2}$ nanoparticle agglomerates by Pseudomonas aeruginosa, Appl. Environ. Microbiol. 76, 7292 (2010).

[48] A Poortinga, J Smit, H van der Mei, H Busscher, Electric field induced desorption of bacteria from a conditioning film covered substratum, Biotechnol. Bioeng. 76, 395 (2001).

[49] A J van der Borden, $\mathrm{H}$ van der Mei, H J Busscher, Electric block current induced detachment from surgical stainless steel and decreased viability of Staphylococcus epidermidis, Biomaterials 26, 6731 (2005).

[50] J Jass, J W Costerton, H M Lappin-Scott, The effect of electrical currents and tobramycin on Pseudomonas aeruginosa biofilms, J. Ind. Microbiol. 15, 234 (1995).

[51] A Valle, E Zanardini, P Abbruscato, P Argenzio, G Lustrato, G Ranalli, C Sorlini, Effects of low electric current (LEC) treatment on pure bacterial cultures, J. Appl. Microbiol. 103, 1376 (2007).

[52] C P Davis, S Weinberg, M D Anderson, G M Rao, M M Warren, Effects of microamperage, medium, and bacterial concentration on iontophoretic killing of bacteria in fluid, Antimicrob. Agents Ch. 33, 442 (1989).
[53] A T Poortinga, R Bos, H J Busscher, Controlled electrophoretic deposition of bacteria to surfaces for the design of biofilms, Biotechnol. Bioeng. 67, 117 (2000).

[54] B A Jucker, H Harms, A J Zehnder, Adhesion of the positively charged bacterium Stenotrophomonas (Xanthomonas) maltophilia 70401 to glass and Teflon, J. Bacteriol. 178, 5472 (1996).

[55] M Ueshima, S Tanaka, S Nakamura, K Yamashita, Manipulation of bacterial adhesion and proliferation by surface charges of electrically polarized hydroxyapatite, J. Biomed. Mater. Res. 60, 578 (2002).

[56] M R Asadi, G Torkaman, Bacterial inhibition by electrical stimulation, Adv. Wound Care 3, 91 (2014).

[57] F Y Ahmed, U F Aly, R M A El-Baky, N G F M Waly, Effect of titanium dioxide nanoparticles on the expression of efflux pump and quorum-sensing genes in MDR Pseudomonas aeruginosa isolates, Antibiotics 10, 625 (2021).

[58] A Krasowska, K Sigler, How microorganisms use hydrophobicity and what does this mean for human needs?, Front. Cell. Infect. Microbiol. 19, 112 (2014).

[59] J Hu, J Lin, Y Zhang, Z Lin, Z Qiao, Z Liu, W Yang, X Liu, M Dong, Z Guo, A new antibiofilm strategy of enabling arbitrary surfaces of materials and devices with robust bacterial anti-adhesion via a spraying modified microsphere method, J. Mater. Chem. A. 7, 26039 (2019).

[60] Y Mu, H Zeng, W Chen, Quercetin inhibits biofilm formation by decreasing the production of EPS and altering the composition of EPS in Staphylococcus epidermidis, Front. Microbiol. 12, 251 (2021).

[61] R Shah, S Kaewgun, B Lee, T Tzeng, The antibacterial effects of biphasic brookiteanatase titanium dioxide nanoparticles on multiple-drug-resistant Staphylococcus aureus, J. Biomed. Nanotechnol. 4, 339 (2008). 
PAPers in Physics, vol. 13, ART. 130005 (2021) / M. M. Shawki et al.

[62] P Dhandapani, S Maruthamuthu, G Rajagopal, Bio-mediated synthesis of $\mathrm{TiO}_{2}$ nanoparticles and its photocatalytic effect on aquatic biofilm, J. Photochem. Photobiol. B Biol. 110, 43 (2012).

[63] J Rajkumari, C M Magdalane, et al., Synthesis of titanium oxide nanoparticles using Aloe barbadensis mill and evaluation of its antibiofilm potential against Pseudomonas aeruginosa PAO1, J. Photoch. Photobio. B. 201, 111667 (2019).

[64] K S Landage, G K Arbade, P Khanna, C J Bhongale, Biological approach to synthesize $\mathrm{TiO}_{2}$ nanoparticles using Staphylococcus aureus for antibacterial and anti-biofilm applications, J. Microbiol. Exp. 8, 36 (2020).

[65] A Simon-Deckers, S Loo, et al., Size-, composition- and shape-dependent toxicological impact of metal oxide nanoparticles and carbon nanotubes toward bacteria, Environ. Sci. Technol. 43, 8423 (2009).

[66] J S Guo, P Zhang, Y P Chen, Y Shen, X Hu, $\mathrm{P}$ Yan, J X Yang, F Fang, C Li, X Gao, G X Wang, Microbial attachment and adsorptiondesorption kinetic of tightly bound extracellular polymeric substances on model organic surfaces, Chem. Eng. J. 279, 516 (2015).

[67] P Zhang, J S Guo, P Yan, Y P Chen, W Wang, Y Z Dai, F Fang, J X Wang, Y Shene, Dynamic dispersal of surface layer biofilm induced by nanosized $\mathrm{TiO}_{2}$ based on surface plasmon resonance and waveguide, App. Environ. Microbiol. 84, e00047 (2018).

[68] F Lavaee, $\mathrm{K}$ Faez, $\mathrm{K}$ Faez, N Hadi, F Modaresi, Antimicrobial and antibiofilm activity of silver, titanium dioxide and iron nanoparticles, Americ. J. Dent. 29, 315 (2016).
[69] S Khan, J Ahmad, M Ahamed, J Musarrat, A Al-Khedhairy, Zinc oxide and titanium dioxide nanoparticles induce oxidative stress, inhibit growth, and attenuate biofilm formation activity of Streptococcus mitis, J. Biol. Inorg. Chem. 21, 295 (2016).

[70] S C Marques, J D Rezende, L A Alves, B C Silva, E Alves, L R Abreu, R H Piccoli, Formation of biofilms by Staphylococcus aureus on stainless steel and glass surfaces and its resistance to some selected chemical sanitizers, Braz. J. Microbiol. 38, 538 (2007).

[71] L Zhong, Y Song, S Zhou, The effectiveness of Nafion-coated stainless steel surfaces for inhibiting Bacillus subtilis biofilm formation, Appl. Sci. 10, 5001 (2020).

[72] R Ramachandran, D Sangeetha, Antibiofilm efficacy of silver nanoparticles against biofilm forming multidrug resistant clinical isolates, The Pharma. Innovation 6, 36 (2017).

[73] E Dworniczek, G Plesch, et al., Photocatalytic inactivation of an Enterococcus biofilm: The anti-microbial effect of sulphated and europium-doped titanium dioxide nanopowders, FEMS Microbiol. Lett. 363, fnw051 (2016).

[74] A G Rodrigues, R De Cássia Ruiz, et al., AntiBiofilm action of biological silver nanoparticles produced by Aspergillus tubingensis and antimicrobial activity of fabrics carrying it, Biointerface Res. Appl. Chem. 11, 14764 (2021).

[75] M Eltarahony, M Abu-Serie, H Hamad, S Zaki, $\mathrm{D}$ Abd-El-Haleem, Unveiling the role of novel biogenic functionalized CuFe hybrid nanocomposites in boosting anticancer, antimicrobial and biosorption activities, Sci. Rep. 11, 1 (2021). 